Tropical Journal of Pharmaceutical Research July 2020; 19 (7): 1377-1382

ISSN: $1596-5996$ (print); 1596-9827 (electronic)

(C) Pharmacotherapy Group, Faculty of Pharmacy, University of Benin, Benin City, 300001 Nigeria

\title{
Tiazofurin inhibits oral cancer growth in vitro and in vivo via upregulation of miR-204 expression
}

\author{
Xiaoying Tang ${ }^{1,2}$, Aimin Zhao ${ }^{1,2 *}$, Yanhuan Hong ${ }^{1,2}$ \\ ${ }^{1}$ Department of Pediatric Stomatology, The Affiliated Stomatological Hospital of Nanchang University, No. 49 Fuzhou Road, \\ ${ }^{2}$ The Key Laboratory of Oral Biomedicine, Donghu, Nanchang, Jiangxi 330006, China \\ *For correspondence: Email: RubinGonzaleszip@yahoo.com; Tel: 0086- 0791-6361040
}

Sent for review: 18 January 2020

Revised accepted: 21 June 2020

\begin{abstract}
Purpose: To investigate the effect of tiazofurin on proliferation and growth of oral cancer cells, and the associated mechanism(s) of action.

Methods: The effect of tiazofurin on the cytotoxicity of SCC-VII and SCC-25 oral cancer cells were measured using 3-(4,5-dimethylthiazol-2-yl)-2,5-diphenyltetrazolium bromide (MTT) assay, while cell apoptosis was determined by flow cytometry. Western blotting was used for assaying protein expressions.

Results: Tiazofurin inhibited the viability of the oral cancer cells in a concentration-based manner $(p<0$ .05). Tiazofurin treatment at a dose of $2.0 \mu \mathrm{M}$ reduced the proliferation of SCC-VII and SCC-25 cells to 25 and $22 \%$, respectively. Apoptosis was significantly increased in SCC-VII and SCC-25 cells by tiazofurin treatment, relative to untreated cells $(p<0.05)$. Tiazofurin also increased the activation levels of caspase-3 and caspase-9 and downregulated the expressions of $p$-Akt and p-mTOR in the two cancer cell lines. Moreover, miR-204 expression was significantly promoted in the tiazofurin-treated cells, when compared to control $(p<0$.05). In SCC-VII cells, treatment with tiazofurin suppressed Factin expression, relative to control.

Conclusion: These results demonstrate that tiazofurin inhibits the viability and proliferation of SCC-VII and SCC-25 cancer cells via induction of apoptosis and activation of caspase-3/caspase-9. Moreover, tiazofurin targets Akt/mTOR pathway, and upregulats the expressions of F-actin and miR-204 in the oral carcinoma cells. These findings suggest that tiazofurin has a potential for use as an effective treatment for oral cancer.
\end{abstract}

Keywords: Oral cancer, Tiazofurin, Apoptosis, Caspase, Cytotoxicity

This is an Open Access article that uses a fund-ing model which does not charge readers or their institutions for access and distributed under the terms of the Creative Commons Attribution License (http://creativecommons.org/licenses/by/4.0) and the Budapest Open Access Initiative (http://www.budapestopenaccessinitiative.org/read), which permit unrestricted use, distribution, and reproduction in any medium, provided the original work is properly credited.

Tropical Journal of Pharmaceutical Research is indexed by Science Citation Index (SciSearch), Scopus, International Pharmaceutical Abstract, Chemical Abstracts, Embase, Index Copernicus, EBSCO, African Index Medicus, JournalSeek, Journal Citation Reports/Science Edition, Directory of Open Access Journals (DOAJ), African Journal Online, Bioline International, Open-J-Gate and Pharmacy Abstracts

\section{INTRODUCTION}

Oral cancer initially originates as small lesion from tissues in the mouth, and subsequently grows to a cancerous mass in the oral cavity [1]. In some cases, oral cancer develops from metastatic tumor cells invading oral tissues from distant organs [1]. However, approximately $90 \%$ of oral cancer occur in the lining of the lips and mouth, resulting in what is called squamous cell cancer [2]. Presently, oral cancer is managed with chemotherapy, radiotherapy or resection, either alone or in combination [2]. The survival of oral carcinoma patients is less than $50 \%$, despite 
various treatment techniques [2]. Thus, there is need for effective and novel treatment methods for squamous cell cancers to improve patient survival.

Apoptosis is triggered either by exogenous or endogenous signals, and it regulates cell death [3]. In multicellular organisms, the signals are generated due to aggregated misfolded proteins, irregularity in $\mathrm{Ca}^{2+}$ release, and protein processing in non-specific manner in endoplasmic reticulum [4]. The activation of these stresses for prolonged durations serves as signal for induction of apoptosis [5]. Caspase-3 activation by apoptotic signals in endoplasmic reticulum has crucial role in cellular death and removal of surplus cells [6]. Eukaryotic cells harbor a protein known as cofilin which binds and induces reconstruction of structural framework in actin [7]. The binding of cofilin to actin promotes cellular movement by facilitating pseudopodialike structures [8]. Elevated F-actin has been reported in colon, kidney, prostate and esophageal carcinoma cells [9]. F-Actin also enhances cellular adhesion and migration of localized carcinoma cells in different tissues [10].

Natural products serve as invaluable resources for drug candidates due to their low toxicities in living systems, relative to synthetic drugs. Diverse plant-derived secondary metabolites are included in clinical drug list because of their potential pharmacological properties [11]. Flavonoids exert beneficial influence on human health by reducing risk of disorders via targeting tumor cell proliferative potential and inhibiting inflammation [12]. The current study investigated the anti-proliferative effect of tiazofurin (Figure 1) in oral cancer cells and determined the associated mechanism(s).

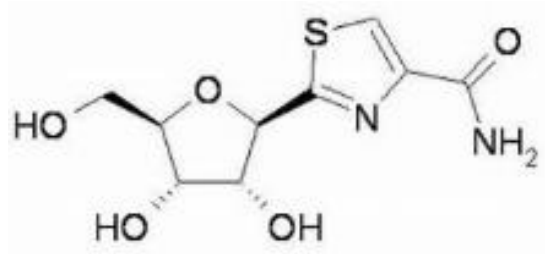

Figure 1: Molecular structure of tiazofurin

\section{EXPERIMENTAL}

\section{Cell culture}

Oral cancer cell lines (SCC-VII and SCC-25) were provided by Cell Bank of the Chinese Academy of Sciences (Shanghai, China). The cells were cultured in DMEM mixed containing 10 $\%$ fetal bovine serum, penicillin $(100 \mu \mathrm{g} / \mathrm{mL})$ and streptomycin $(100 \mu \mathrm{g} / \mathrm{mL})$ in an incubator in a 5 $\% \mathrm{CO}_{2}$ atmosphere at $37^{\circ} \mathrm{C}$.

\section{Cytotoxicity assay}

Cytotoxic changes induced by tiazofurin in the oral cancer cells were measured using 3-(4,5dimethylthiazol-2-yl)-2,5-diphenyltetrazolium

bromide (MTT) assay. The cells were separately seeded in 96-well plates, each at a density of $1 \mathrm{x}$ $10^{6}$ cells/well in DMEM and incubated for $24 \mathrm{~h}$. Tiazofurin was added to the medium at separate doses at $0.25,0.5,0.75,1.0,1.25,1.5,1.75$ and $2.0 \mu \mathrm{M}$, and incubated with the cells for $48 \mathrm{~h}$. Cells treated with only $30 \mathrm{mM}$ HEPES for $48 \mathrm{~h}$ served as negative control. Following incubation, MTT solution ( $5 \mu \mathrm{g} / \mathrm{mL}$ ) was added to each plate, followed by further incubation of the cells for $3 \mathrm{~h}$ at $37{ }^{\circ} \mathrm{C}$. Thereafter, the medium was replaced with $120 \mu \mathrm{l}$ of DMSO to solubilize the formazan crystals formed, and the optical density of each solution was read in an EL800-Microplate Reader at $557 \mathrm{~nm}$. Cell viabilities were estimated from the readings.

\section{Determination of cell apoptosis}

The cells were seeded in 6-well plates, each at a density of $1 \times 10^{5}$ cells/well in DMEM, and were cultured for $24 \mathrm{~h}$ at $37^{\circ} \mathrm{C}$, followed by incubation for $48 \mathrm{~h}$ with $2.0 \mu \mathrm{M}$ tiazofurin. Then, the cells were rinsed twice in PBS, and re-suspended in $300 \mu \mathrm{L}$ of binding buffer. Annexin V-fluorescein isothiocyanate $(5 \mu \mathrm{L})$ was added to each well, and the wells were incubated in the dark at $4{ }^{\circ} \mathrm{C}$ for $40 \mathrm{~min}$. Then, still in the dark, incubation was carried out for $20 \mathrm{~min}$ with $10 \mu \mathrm{LPI}$ at room temperature. Cellular apoptosis was analyzed using FACSCalibur flow cytometer equipped with Flowjo software.

\section{Determination of caspase activities}

The cells were seeded at density of $1 \times 10^{5}$ cells/well in a96-well plate and treated with tiazofurin at a dose of $2.0 \mu \mathrm{M}$. Then, the cells were incubated for $48 \mathrm{~h}$ at $37{ }^{\circ} \mathrm{C}$, followed by addition of $130 \mu \mathrm{L}$ commercially-available caspase- 3 and caspase- 9 reagents (Beyotime Institute of Biotechnology). Thereafter, incubation was carried out for $3 \mathrm{~h}$ at room temperature, and absorbance was read at $488 \mathrm{~nm}$ in a microplate reader (Bio-Rad Laboratories, Inc.). The readings were used for estimation of caspase levels.

\section{Western blotting analysis}

The cells were seeded at a density of $1 \times 10^{6}$ cells/well in 6-well plates and treated for $48 \mathrm{~h}$ with $2.0 \mu \mathrm{M}$ tiazofurin. Following rinsing with 
PBS, the cells were lysed in RIPA buffer, and the protein content of the lysate was determined using BCA protein assay kit (Thermo Fisher

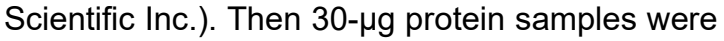
resolved on 10-12 \% SDS-PAGE and transferred to PVDF membranes. The membranes were treated with $5 \%$ non-fat milk in TBST at $37{ }^{\circ} \mathrm{C}$, to block non-specific binding of the blot. Then, the membrane was incubated overnight with primary antibodies i.e. anti-p-Akt, anti-Akt, anti-p-mTOR, anti-mTOR and anti-F-actin at $4^{\circ} \mathrm{C}$, followed by incubation with horseradish peroxidaseconjugated secondary antibody for $2.5 \mathrm{~h}$ at room temperature. The blots were detected using enhanced chemiluminescence (ECL) and analyzed with Image Lab software.

\section{Statistical analysis}

Results are expressed as mean \pm standard deviation (SD) of three experiments performed independently. Statistical analysis was done using SPSS software (version 17.0; SPSS, Inc., Chicago, IL, USA). Differences were determined using Students $t$-test, one-way analysis of variance (ANOVA) and Tukey's post-hoc test. Values of $p<0.05$ were taken as indicative of statistically significant differences.

\section{RESULTS}

Tiazofurin inhibited SCC-VII and SCC-25 cell proliferation

Tiazofurin exhibited cytotoxic effect on viabilities of SCC-VII and SCC-25 cells in a concentrationbased manner (Figure 2). Tiazofurin treatment at doses of $0.25,0.5,0.75,1.0,1.25,1.5,1.75$ and $2.0 \mu \mathrm{M}$ reduced SCC-VII cell proliferation to 93 , $85,75,60,48,41,34$ and $25 \%$, respectively. The levels of viability of SCC- 25 cells were 91 , $82,70,59,44,39,31$ and $22 \%$, on treatment with tiazofurin at doses of $0.25,0.5,0.75,1.0$, $1.25,1.5,1.75$ and $2.0 \mu \mathrm{M}$, respectively. Thus, tiazofurin suppressed the proliferative potential of the oral carcinoma cells in a concentrationdependent manner.

\section{Tiazofurin induced apoptosis in SCC-VII and SCC-25 cells}

Values of percentage apoptosis were significantly increased in SCC-VII and SCC-25 cells by tiazofurin treatment, relative to untreated control $(p<0.05$; Figure 3). Apoptosis in tiazofurin treated SCC-VII cells increased to $68.71 \%$ on treatment with $2.0 \mu \mathrm{M}$ dose, relative to $1.98 \%$ in control cells. Treatment with tiazofurin at $2.0 \mu \mathrm{M}$ increased apoptotic in SCC25 cells to $70.46 \%$ relative to $2.56 \%$ in control cells. Thus, tiazofurin exhibited cytotoxic effect on the oral carcinoma cells by activating apoptosis.

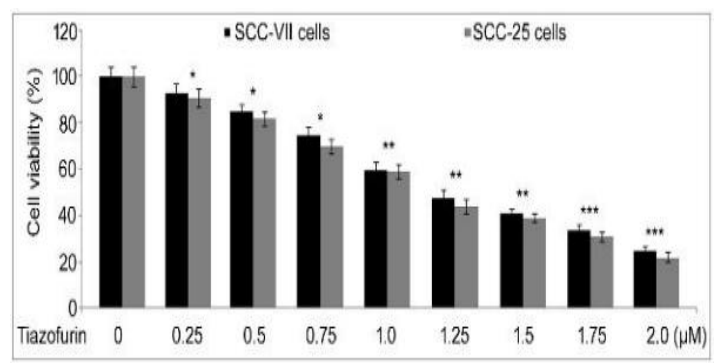

Figure 2: Effect of tiazofurin on the viability of oral carcinoma cells. The SCC-VII and SCC- 25 cells were treated with tiazofurin at indicated doses, and viability measurements were made using MTT assay; * $p<$ $0.05 ;{ }^{* *} p<0.02 ;{ }^{* * *} p<0.01$, vs. untreated treated cells

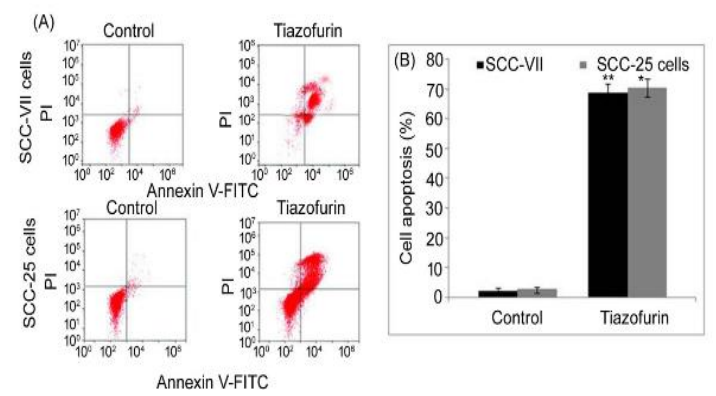

Figure 3: Effect of tiazofurin on apoptosis in oral carcinoma cells. The SCC-VII and SCC- 25 cells were treated with $2.0 \mu \mathrm{M}$ tiazofurin and apoptosis was assayed using flow cytometry. ${ }^{*} P<0.02$; ${ }^{* *} p<0.01$, vs untreated cells

\section{Tiazofurin activated caspase -3 and caspase- 9 activities in SCC-VII and SCC-25 cells}

The effect of tiazofurin on the activities of caspase- 3 and caspase- 9 in SCC-VII and SCC25 cells was assayed with western blot assay (Figure 4). Tiazofurin at a dose of $2.0 \mu \mathrm{M}$ markedly activated caspase-3activities in SCCVII and SCC-25 cells, relative to control cells. Moreover, it significantly activated caspase-9 activities in SCC-VII and SCC-25 cells, when compared to untreated cells.

\section{Tiazofurin suppressed Akt activation in SCC- VII and SCC-25 cells}

Changes in p-Akt and Akt levels in SCC-VII and SCC-25 cells due to tiazofurin treatment were assayed using western blotting cells (Figure 5). The expressions of p-Akt in $2.0 \mu \mathrm{M}$ tiazofurintreated SCC-VII and SCC-25 cells were suppressed markedly, relative to control cells. However, tiazofurin treatment caused no 
changes in expressions of total Akt protein in SCC-VII and SCC-25 cells.

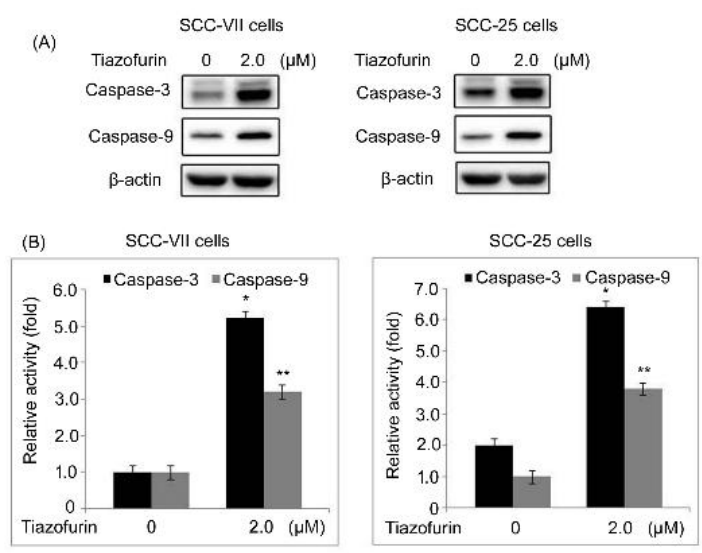

Figure 4: Effect of tiazofurin on caspase-3 and caspase- 9 activities in SCC-VII and SCC- 25 cells, as assayed using western blotting. ${ }^{*} P<0.02$; ${ }^{* *} p<0.01$, vs. untreated cells

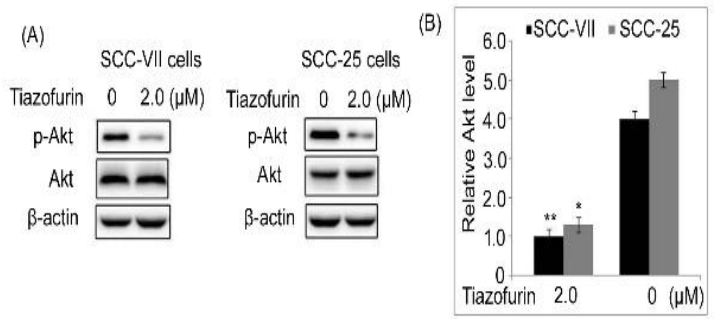

Figure 5: Effect of tiazofurin on Akt and p-Akt expressions. (A) SCC-VII and SCC-25 cells were treated with tiazofurin at a dose of $2.0 \mu \mathrm{M}$, and the expressions of p-Akt and Akt were determined with western blot assay. (B) Densitometric data for p-Akt and Akt expressions. ${ }^{*} P<0.02 ;{ }^{* *} p<0.01$, vs untreated cells

\section{Tiazofurin suppressed $p$-mTOR expressions in SCC-VII and SCC-25 cells}

Changes in p-mTOR expression due to tiazofurin treatment were assayed with western blotting in SCC-VII and SCC-25 cells (Figure 6). The expression of p-mTOR in $2.0 \mu \mathrm{M}$ tiazofurintreated SCC-VII and SCC-25 cells were suppressed markedly, relative to untreated cells. However, tiazofurin treatment caused no changes in expressions of total mTOR protein in SCC-VII and SCC-25 cells.

Tiazofurin inhibited F-actin expressions in SCC-VII and SCC-25 cells

The expressions of $\mathrm{F}$-actinin tiazofurin-treated SCC-VII and SCC-25 cells were assayed with western blotting technique. In SCC-VII cells, treatment with $2.0 \mu \mathrm{M}$ tiazofurin markedly suppressed F-actin expression, relative to control. The F-actin expression in SCC-25 cells was also reduced by treatment with $2.0 \mu \mathrm{M}$ tiazofurin. These results are shown in Figure 7.

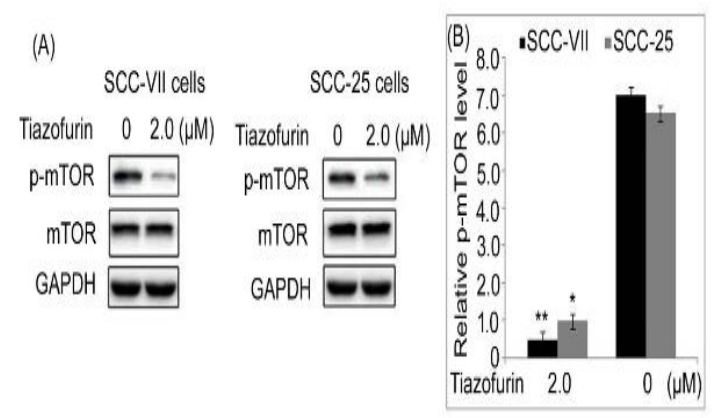

Figure 6: Effect of tiazofurin on p-mTOR expression. (A) SCC-VII and SCC-25 cells were treated with tiazofurin at a dose of $2.0 \mu \mathrm{M}$, and p-mTOR expression was measured with western blot assay. (B) Densitometric data for p-Akt and Akt expression. ${ }^{*} P<$ $0.02 ;{ }^{* *} p<0.01$, vs. untreated cells

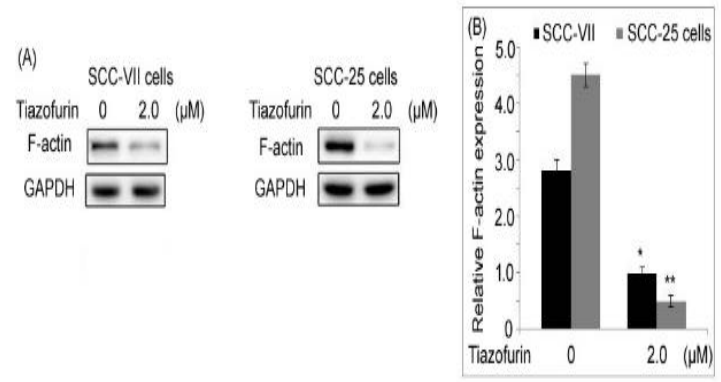

Figure 7: Effect of tiazofurin on F-actin expression. (A) The SCC-VII and SCC-25 cells were treated with tiazofurin at a dose of $2.0 \mu \mathrm{M}$, and F-actin expression was measured using western blotting assay. (B) Densitometric data for F-actin expression; ${ }^{*} p<0.02$ and ${ }^{* *} p<0.01$ vs. $0 \mu \mathrm{M}$ tiazofurin-treated cells

\section{DISCUSSION}

Oral cancer belongs to the category of head and neck carcinoma and is the $6^{\text {th }}$ most commonly diagnosed malignancy throughout the world [13]. It is the fourth highest cause of death related to cancer in males, and it ranks highest in mortality among people of young age in Taiwan [14]. Although diagnostic techniques and screening processes have improved significantly over the years, morbidity due to oral cancer has increased significantly in recent years in Asian countries and China [15]. In the present study, tiazofurin significantly suppressed the viabilities of SCC-VII and SCC-25 cells in dose-based manner, and significantly induced apoptosis in the cancer cells, relative to untreated control cells. Stressmediated caspase activation in endoplasmic reticulum initially enhances mitochondrial 
permeability, with subsequent cytochrome c efflux [16]. This is immediately followed by apoptotic complex formation, cleavage of effector caspases, and cellular apoptosis [6]. The current study showed that tiazofurin markedly elevated caspase-3 and caspase -9 activities in SCC-VII and SCC-25 cells, relative to untreated cells.

Protein synthesis for multiple functions (including cell survival) is regulated by the mTOR pathway which serves as an important target for treatment of various cancers [17]. The PI3K/Akt pathway which regulates cellular proliferation and viability uses mTOR as a downstream effector [17]. Autophagic death has been reported in multidrug-resistant lung cancer cells via inhibition of the Akt/mTOR pathway [18]. In the current study, tiazofurin reduced phosphorylation of Akt (p-Akt) in SCC-VII and SCC-25 cells without influencing total Akt expressions. Tiazofurin treated SCC-VII and SCC-25 cells also showed lower level of p-mTOR, relative to untreated cells. This suggests that tiazofurin inhibited the growth of SCC-VII and SCC-25 cells by targeting the Akt/mTOR pathway.

The internal proteins in cells like microfilaments and canaliculi together comprise the cytoskeleton framework [19]. Among the structural constituents of the cytoskeleton, microfilaments are the smallest units, and they consist of globular-form actin protein called F-actin [19]. The data from the present study have shown that tiazofurin treatment suppressed expression of Factin in the two oral cancer cells. MicroRNAs (miRNAs) contribute to the development of various cancers, including gastric carcinoma [20]. These microRNAs are involved in regulation of target genes via suppression of translation or degradation of mRNAs [21]. Studies have shown that miR-204 expression is markedly downregulated in carcinoma cells [22]. Therefore, elevation of miR-204 expression has therapeutic role in treatment of cancers. The present study demonstrated that tiazofurin induced upregulation of miR-204 expression in SCC-VII and SCC-25oral cancer cells.

\section{CONCLUSION}

The findings in this study demonstrate the inhibitory effect of tiazofurin on oral cancer cells via induction of apoptosis and activation of caspase-3 and caspase-9. Furthermore, tiazofurin targets the Akt/mTOR pathway, and elevates the expressions of F-actin and miR-204 in oral carcinoma cells. These results suggest that tiazofurin may be an effective therapeutic agent for oral cancer.

\section{DECLARATIONS}

\section{Conflict of interest}

No conflict of interest is associated with this work.

\section{Contribution of authors}

We declare that this work was done by the author(s) named in this article and all liabilities pertaining to claims relating to the content of this article will be borne by the authors. Aimin Zhao conceived and designed the study; Xiaoying Tang, Yanhuan Hong - collected and analyzed the data; Xiaoying Tang, Aimin Zhao -wrote the manuscript. All authors read and approved the manuscript for publication.

\section{Open Access}

This is an Open Access article that uses a funding model which does not charge readers or their institutions for access and distributed under the terms of the Creative Commons Attribution License (http://creativecommons.org/licenses/by/ 4.0) and the Budapest Open Access Initiative (http://www.budapestopenaccessinitiative.org/rea d), which permit unrestricted use, distribution, and reproduction in any medium, provided the original work is properly credited.

\section{REFERENCES}

1. Koch WM, Stafford E, Bajaj G. Cancer of the oral cavity. Part A: General principles and management. In: Head and neck cancer: A multidisciplinary approach. Harrison $L B$, Sessions RB, Hong WK (Eds). 3rd edn. Lippincott Williams and Wilkins, Philadelphia, PA 2009; 250-265.

2. Feller L, Lemmer J. Oral squamous cell carcinoma: Epidemiology, clinical presentation and treatment. $J$ Cancer Ther 2012; 3: 263-268.

3. Raff MC, Barres BA, Burne JF, Coles HS, Ishizaki Y, Jacobson MD. Programmed cell death and the control of cell survival: Lessons from the nervous system. Science 1993; 262: 695-700.

4. Obakan P, Arisan ED, Coker-Gurkan A, Palavan-Unsal N. Epibrassinolide-induced apoptosis regardless of p53 expression via activating polyamine catabolic machinery, a common target for androgen sensitive and insensitive prostate cancer cells. Prostate 2014; 74: 1622-1633.

5. Reshma RS, Sreelatha $K H$, Somasundaram $V$, Satheesh Kumar S, Nadhan R, Nair RS, Srinivas P. Plumbagin, a naphthaquinone derivative induces apoptosis in BRCA $1 / 2$ defective castrate resistant prostate cancer cells as well as prostate cancer stem-like cells. Pharmacol Res 2016; 105: 134-145.

Trop J Pharm Res, July 2020; 19(7): 1381 
6. Kwegyir-Afful AK, Ramalingam S, Purushottamachar $P$, Ramamurthy VP, Njar VC. Galeterone and VNPT55 induce proteasomal degradation of $A R / A R-V 7$, induce significant apoptosis via cytochrome $C$ release and suppress growth of castration resistant prostate cancer xenografts in vivo. Oncotarget 2015; 6: 27440-27460.

7. Zhu B, Fukada K, Zhu H, Kyprianou N. Prohibitin and cofilin are intracellular effectors of transforming growth factor beta signaling in human prostate cancer cells. Cancer Res 2006; 66: 8640-8647.

8. Lu LI, FU NI, Luo XU, Li XY, Li XP. Overexpression of cofilin 1 in prostate cancer and the corresponding clinical implications. Oncol Lett 2015; 9: 2757-2761.

9. Sundram V, Chauhan SC, Ebeling M, Jaggi M. Curcumin attenuates $\beta$-catenin signaling in prostate cancer cells through activation of protein kinase D1. PLoS One 2012; 7: e35368.

10. Bokobza SM, Ye L, Kynaston HG, Jiang WG. Growth and differentiation factor-9 promotes adhesive and motile capacity of prostate cancer cells by up-regulating FAK and Paxillin via Smad dependent pathway. Oncol Rep 2010; 24: 1653-1659.

11. Greenwell M, Rahman PK. Medicinal plants: their use in anticancer treatment. Int J Pharmaceut Sci Res 2015; 6(10): 4103.

12. Craig WJ. Health-promoting properties of common herbs. American J Clin Nut 1999; 70(3): 491s-9s.

13. Petersen PE. Strengthening the prevention of oral cancer: the WHO perspective. Community Dent Oral Epidemiol 2005; 33: 397-399.

14. Kao SY, Lim E. An overview of detection and screening of oral cancer in Taiwan. The Chin J Dent Res 2015; 18: 7-12.

15. Matsumoto K, Hagiwara M, Tanaka N, Hayakawa N, Ishida M, Ninomiya A, Nakajima Y, Nakamura S. Survival following primary androgen deprivation therapy for localized intermediate- or high-risk prostate cancer: Comparison with the life expectancy of the age-matched normal population. Med Oncol 2014; 31: 979.

16. Cella D, Ivanescu C, Holmstrom S, Bui CN, Spalding J, Fizazi K. Impact of enzalutamide on quality of life in men with metastatic castration-resistant prostate cancer after chemotherapy: Additional analyses from the AFFIRM randomized clinical trial. Ann Oncol 2015; 26: 179-185.

17. Fang $F$, Wang $L$, Zhang $S$, Fang $Q$, Hao $F$, Sun $Y$, Zhao L, Chen S, Liao H, Wang L. CD147 modulates autophagy through the PI3K/Akt/mTOR pathway in human prostate cancer PC-3 cells. Oncol Lett 2015; 9: 1439-1443.

18. Chiu LY, Hu ME, Yang TY, Hsin IL, Ko JL, Tsai KJ, Sheu GT. Immunomodulatory protein from ganoderma microsporum induces pro-death autophagy through AktmTOR-p70S6K pathway inhibition in multidrug resistant lung cancer cells. PLoS One 2015; 10: e0125774.

19. Asahara S, Shibutani Y, Teruyama K, Inoue HY, Kawada $Y$, Etoh H, Matsuda T, Kimura-Koyanagi M, Hashimoto $N$, Sakahara $M$, et al. Ras-related C3 botulinum toxin substrate 1 (RAC1) regulates glucose-stimulated insulin secretion via modulation of F-actin. Diabetologia 2013; 56: 1088-1097.

20. Qiu T, Zhou X, Wang J, Du Y, Xu J, Huang Z, Zhu W, Shu Y, Liu P. MiR-145, miR-133a and miR-133b inhibit proliferation, migration, invasion and cell cycle progression via targeting transcription factor $\mathrm{Sp} 1$ in gastric cancer. FEBS Lett 2014.

21. Xie M, Li M, Vilborg A, Lee N, Shu MD, et al. Mammalian 59-capped microRNA precursors that generate a single microRNA. Cell 2013; 155: 1568-1580.

22. Schepers GE, Teasdale RD, Koopman P. Twenty pairs of sox: extent, homology, and nomenclature of the mouse and human sox transcription factor gene families. Dev Cell 2002; 3: 167-170. 